\title{
Laser treatment for anal fistulas: what are the pitfalls?
}

\section{P. Giamundo ${ }^{1}$}

Received: 10 April 2020 / Accepted: 11 April 2020 / Published online: 2 May 2020

(c) Springer Nature Switzerland AG 2020

Laser treatment for fistula-in-ano, also known as $\mathrm{FiLaC}^{\mathrm{R}}$ (fistula laser closure) or LAFT (laser ablation of fistula tract), has gained increasing attention in the last decade.

The procedure consists of delivering laser energy at $360^{\circ}$ within the lumen of fistulas by means of a radial fiber which is slowly withdrawn from the external orifice. Laser ablation is limited to the lumen of fistulas making the technique 'sphincter-saving'.

Its main indication is the treatment of high fistulas and, in general, of all fistulas where more invasive treatments may impair anal continence.

Since 2011, after a German group published the first pilot study [1], clinical results of this minimally invasive procedure were reported in a few papers, prompting growing interest in this novel technique in the scientific community. As for most procedures, the literature showed controversial results over the years. Following the first encouraging results [1-5], some studies reported a high percentage of failures [6-9]. This raised some concerns and led to the consideration that the destiny of the procedure was similar to that of many others: the initial enthusiasm was followed by a high, yet unexpected, disappointing future at long-term followups. However, a few considerations need to be stressed.

First of all, the results of a few studies showed a variable percentage of success but longer follow-ups were not necessarily associated with higher recurrence rate [4, 8]. Interestingly, in most series, the failures after FiLaC were in the form of 'non-healing' or persistence of the fistula tract rather than recurrence.

Therefore, attention needs to be focused primarily on the efficacy of the procedure and not to failure in the long term like for other sphincter-saving treatments (fibrin glue, plugs).

P. Giamundo

pgiamundo@gmail.com

1 Department of Colorectal Surgery, Policlinico di Monza, Monza, Italy
Why success rates differ significantly between different studies may have several explanations and these need to be analyzed.

The great variability in type, length and size of the fistulas treated may play a major role in affecting the success rate.

The shrinkage of fistula tracts caused by laser depends on the wavelength and the amount of energy of the laser beam delivered within the tract. With the parameters used by most centers, the shrinking effect should successfully heal fistulas with a diameter of maximum $4-5 \mathrm{~mm}$. There is no guarantee of efficiency for larger fistulas. This would explain some failures in a few studies.

De Bonnechose et al. [10], in the current issue of Techniques in Coloproctology, reported fistula healing in $44.6 \%$ of patients. In this study, fistulas with a large internal orifice had only a $15 \%$ healing rate compared to $49 \%$ healing in fistulas with a narrow internal opening. However, the fistula diameter is difficult to measure. In the study by De Bonnechose, even the diameter of the internal orifice is subjectively measured, based on how tight the orifice is around the fistula probe [10]. The size of internal orifice may have poor correlation with the diameter of the fistula tract.

In our experience, we found that curettage and insertion of a silastic drain in the lumen of the fistula in a firststage operation as bridge to laser treatment (second stage, 12 weeks later) may induce the formation of fibrotic tissue, "modeling" the fistula around the draining loop. This process would help reach the optimal width and caliber (4 mm.) making the fistulas more suitable for the following laser treatment.

The length of the fistula tract may also play a role in influencing the success rate. In this regard, results in the literature are rather controversial. While some authors consider the length of the fistula the 'Achille's heel' of laser treatment [6], we have a different opinion based on our experience: the longer the fistula the better the shrinkage effect elicited by laser energy. This finding has been confirmed in a recent study [8]. The concept is based on the assumption that the presence of a longer tract around the sphincters increases the 
chance of tract closure as opposed to a short tract crossing only small amounts of soft adipose tissue.

A few other controversial questions regarding the procedure have been raised over the years. One of the most important regards the closure of the internal opening. The addition of an advancement flap to laser treatment was proposed to close the internal orifice $[1,5]$. Although we agree that it is important to treat the internal orifice, we believe that the shrinkage effect of laser on the internal opening of the fistula is sufficient to cause its sealing. Therefore, we did not add other procedures to laser.

However, this assertion is not cast in stone. It is reasonable to consider the closure of the internal orifice (with direct suture or flaps) in case of 'wide' orifices, as suggested by De Bonnechose in the discussion, when the internal orifice is larger than laser probe [10], especially if the surrounding area is well vascularized and not fibrotic.

Another controversial point is how much energy we should use to close the fistula. This is not easy to establish. First of all, it is crucial to understand that, to have more precise and reproducible parameters, the amount of energy delivered per centimeter of fistula should be measured. In fact, the measurement of the total amount of Joules delivered in a single procedure can be misleading as it depends on the energy settings, the length of the fistula and the speed of the fiber withdrawal. De Bonnechose et al. in the current study did not standardize the amount of joules per $\mathrm{cm}$; however, when they calculated the total amount of joules per fistula, they found that fistulas requiring less than $400 \mathrm{~J}$ had a higher healing rate compared to fistulas requiring more than $400 \mathrm{~J}$ ( $65 \%$ vs $32 \%$, respectively). Delivering too much laser energy to a few millimeters of tissue may result in overburning the fistula with the potential effect of increasing the caliber of the tract hampering the shrinking effect of the laser as suggested by the authors [10]. On the other hand, too little energy could be insufficient to close the tract.

Apparently, there is a rather significant variation in the amount of energy used in different studies although the parameters used are often unclear. If we consider the number of joules delivered/cm, Ozturk [3] used approximately $90 \mathrm{~J} / \mathrm{cm}$; Wilhelm, $39 \mathrm{~J} / \mathrm{cm}$ [5]; while in our experience, approximately $120 \mathrm{~J} / \mathrm{cm}$ was delivered [4]. When De Bonnechose et al. examined the healing rate according to joules per $\mathrm{cm}$, they found only a statistical trend [10] indicating that this crucial component of the laser technique is still an open question.

The effect of laser within the lumen of the fistula is not visible.

This may be considered one of the biggest pitfalls of the technique. Being a "blind" procedure, the shrinkage effect cannot be 'controlled' and the difficulty in calibrating the amount of energy delivered per $\mathrm{cm}$ of fistula tract makes the procedure difficult to reproduce. The feeling of "resistance" while withdrawing the fiber from the fistula tract may be helpful in indicating the shrinkage of the tract around the fiber. Intraoperative anal ultrasound may also give some additional contribution to establish the efficacy of fistula shrinkage, but the importance of its routine use during FiLaC needs to be demonstrated.

Another questionable point is the treatment of the external orifice. By intuition, the distal part of the fistula, partly crossing the ischiorectal fossa, extending from the external margin of the external sphincter to the external orifice of the fistula has lower potential for successful shrinkage by means of laser. This is mainly due to the soft and less fibrotic tissue surrounding the distal and subcutaneous part of the fistula tract which is less 'sensitive' to the shrinkage effect delivered by the intraluminal laser beam. In this regard, a core excision of the distal tract of the fistula, including the external orifice may be a solution in selected cases.

Interestingly, a "downgrading" in the fistulas' height after laser treatment was reported in some studies $[4,5]$. This would make fistulas more suitable for a second treatment. Fistulotomy or redo-laser treatment can be successfully performed in case of recurrence with higher secondary success rates.

Finally, it is very interesting that most studies report significant improvement of the severity of symptoms even in those patients who experience reduced yet persistent discharge from the external orifice $[4,5,7]$. This is the reason why, in our experience, some of the patients refused to undergo further treatments even if they were not 'completely' cured. These findings and the results of some published trials may encourage the use of laser treatment also in Crohn's patients, in addition to conservative treatments $[5,11]$.

\section{Compliance with ethical standards}

Conflict of interest The author declares that he is 'surgical trainer' for Biolitec Biotechnology, Germany.

Ethical approval This article does not contain results of studies with human participants or animals performed by the Author.

Informed consent For this type of study, no informed consent is required.

\section{References}

1. Wilhelm A (2011) A new technique for sphincter-preserving anal fistula repair using a novel radial emitting laser probe. Tech Coloproctol 15:445-449

2. Giamundo P, Geraci M, Tibaldi L, Valente M (2014) Closure of fistula-in-ano with laser-FiLaC ${ }^{\mathrm{TM}}$ : an effective novel 
sphincter-saving procedure for complex disease. Colorectal Dis $16: 110-115$

3. Öztürk E, Gülcü B (2014) Laser ablation of fistula tract: a sphincter-preserving method for treating fistula-in-ano. Dis Colon Rectum 57:360-364

4. Giamundo P, Esercizio L, Geraci M, Tibaldi L, Valente M (2015) Fistula-tract laser closure $\left(\mathrm{FiLaC}^{\mathrm{TM}}\right)$ : long-term results and new operative strategies. Tech Coloproctol 19:449-453

5. Wilhelm A, Fiebig A, Krawczak M (2017) Five years of experience with the FiLaC ${ }^{\mathrm{TM}}$ laser for fistula-in-ano management: long-term follow-up from a single institution. Tech Coloproctol 21:269-276

6. Lauretta A, Falco N, Stocco E, Bellomo R, Infantino A (2018) Anal fistula laser closure: the length of fistula is the Achilles' heel. Tech Coloproctol 22:933-939

7. Terzi MC, Agalar C, Habip S, Canda AE, Arslan NC, Obuz F (2018) Closing perianal fistulas using a laser: long-term results in 103 patients. Dis Colon Rectum 61:599-603

8. Marref I, Spindler L, Aubert M, Lemarchand N, Fathallah N, Soudan D et al (2019) The optimal indication for FiLaC® is high trans-sphincteric fistula-in-ano: the study of a prospective cohort of 69 consecutive patients. Tech Coloproctol 23:893-897
9. Stijns J, van Loon YT, Clermonts SHEM, Gottgens KW, Warsowicz DK, Zimmermann DDE (2019) Implementation of laser ablation of fistula tract (LAFT) for perianal fistola: do the results warrant continued application of this technique? Tech Coloproctol 23:1127-1132

10. De Bonnechose G, Lefevre JH, Auber M, Lemarchand N, Fathallah N, Pommaret E, Soudan D, Spindler L, de Parades V (2020) Laser ablation of fistula tract (LAFT) and complex fistula-in-ano: the ideal indication is becoming clearer. Tech Coloproctol. https ://doi.org/10.1007/s10151-020-02203-y

11. Alam A, Lin F, Fathakkah N, Pommaret E, Aubert M, Lemarchand N, Abbes L, Spindler L, Portal A, De Parades V (2020) FiLaC and Crohn's disease perianal fistola: a pilot study of 20 consecutive patientys. Tech Coloproctol 24:75-78

Publisher's Note Springer Nature remains neutral with regard to jurisdictional claims in published maps and institutional affiliations. 